\title{
Innovations in the continuing professional development of foreign language teachers: from blended learning to visual-based learning, choices of emotional and instructional designs ${ }^{1}$
}

\author{
Valentina Toci ${ }^{\text {a }}$
}

${ }^{a}$ INDIRE,Italy,v.toci@indire.it

\begin{abstract}
In this study, starting from the profile of our trainees and from the risks highlighted by some studies in terms of the use of video in education, we will analyse the motivations and choices behind the development of the online training model for Foreign Language teachers. We will show how, in order to cope with the impossibility of continuing with blended training, we were directed to a model more closely linked with visual-based learning. We explain our instructional and emotional design choices to support and direct our teacher trainees to flexible learning and the use of media and Web 2.0 in their classrooms. Finally, we investigate the possible problems in terms of sustainability and technical feasibility, comparing the development of two prototypes of videos made using the techniques of video scribing and whiteboard animation: a video interview and a video animation.
\end{abstract}

Keywords:

continuous professional development, educational video, video-scribing, whiteboard animation, flexible learning

\section{Introduction}

In 2008, the National Operational Programme (henceforth, NOP) 2007-2013 and the European Social Fund cofunded a Professional Development Project (administered by the Italian Ministry of Education), for lower secondary school teachers.

Language, literature and culture in a European dimension is a training course for teachers of foreign languages (henceforth, FLs), with contents in English, French, Spanish and German. The course is designed based on programmatic documents concerning the National Education System Reform issued by the Italian Ministry. Its implementation during the school year allowed the trainees to experience a situated learning, rooted in daily teaching practices, and to reflect upon their teaching approach and methodological innovation in an action -research process.

The training methodology ${ }^{2}$ has been a 'blended' one, consisting of 100 hours ( 80 online and 20 face-to-face), with group meetings with a tutor, experimental activities and Web activities.

The syllabus, containing alternating theory and practice sections, is articulated as 'Theoretical Unit' and "Learning Path" (henceforth, LP), which comprise the strategic elements of the training.

Since 2007-2008, training contents were developed for teachers of lower secondary school, and the contents were extended to those of upper secondary school since 2010, with the continuation of the reform process.

A key aspect of this extension was that with the end of the NOP, it would not be possible anymore to activate courses as in the past.

In this study, we analyse the training model and aspects of 'Instructional design' used in the first phase of the project. Moreover, we show how, in order to cope with the impossibility of continuing the courses, we were directed to a model that is closely linked with the visual-based learning (VBL) approach and based on the principle of the emotional design.

\footnotetext{
${ }^{1}$ I would like to thank my colleague Mrs. Laura Coscia for the effort she has put into the project.

2 For more details, see 'A training model for professional development of teachers in Italian Southern Regions'(:http://www.sie1.it/phocadownload/Atti_siel_2014.pdf).
} 


\section{Innovations in the continuing professional development of foreign language teachers: from blended learning to visual-based learning, choices of emotional and instructional designs Toci}

\section{The first model of LPs: choices and motivations behind the design}

The first LP was developed in 2007 -2008 with the collaboration of professional teachers.

\begin{tabular}{|c|c|c|c|c|}
\hline Trainees & \multicolumn{4}{|c|}{ Lower secondary school teachers of FL } \\
\hline Context of use & \multicolumn{4}{|l|}{ In-service training } \\
\hline $\begin{array}{l}\text { Methodological } \\
\text { and training } \\
\text { approach }\end{array}$ & \multicolumn{4}{|c|}{$\begin{array}{l}\text { - Blendedleaming } \\
\text { - Reflective and experiential leaming } \\
\text { - Balance between teacher professional development and the improvement of the disciplinary skills of } \\
\text { the students in the classroom }\end{array}$} \\
\hline Content & \multicolumn{4}{|c|}{$\begin{array}{l}\text { - Focus on the fundamental aspects of the discipline and on the problems and issues in curiculum } \\
\text { development } \\
\text { - Ample downloadable documentation for classroom activities }\end{array}$} \\
\hline Design & \multicolumn{4}{|c|}{$\begin{array}{l}\text { - Hypertext full of content (mainly texts, with the instrumentaluse of media and graphic elements) } \\
\text { - Browsing through a navigation map }\end{array}$} \\
\hline Architecture & $\begin{array}{l}\text { Introduction; } \\
\text { General aim; } \\
\text { Teachers' and } \\
\text { Students' learning } \\
\text { objectives. }\end{array}$ & $\begin{array}{l}\text { Proposal for } \\
\text { working } \\
\text { methodology }\end{array}$ & $\begin{array}{l}\text { Step } 2 \\
\text { Presentation of the teaching } \\
\text { strategies to be adopted with } \\
\text { students } \\
\text { 2.1) Classroom activity (with } \\
\text { methods, strategies, tools) } \\
\text { articulated in steps; } \\
\text { 2.2) Resources to support } \\
\text { classroom activities }\end{array}$ & $\begin{array}{l}\text { Assessment tools for } \\
\text { teachers' and students' } \\
\text { learning outcome } \\
\text { Short summary in } \\
\text { Italian }\end{array}$ \\
\hline
\end{tabular}

Fig. 1 The first model of the learning paths

The contents initially developed consisted of articulated hypertexts, as we counted on a tutor to smoothly introduce new ideas for the use of information and communications technology (ICT) in classrooms (Coscia, 2016). Computers and multimedia have been used for language teaching even since the 1960s: we have evolved from Web 1.0 to 2.0; from computer-assisted language learning to MALL (mobile-assisted language learning), referring to learning mediated via handheld devices and potentially available anytime, anywhere.

However, our teachers were familiar with the use of Web 1.0 (Parigi \& Rossi, 2010), but unfamiliar with Web 2.0, as highlighted by the survey conducted in 2009 on users of the online community INDIRE 'FOR' open to Italian teachers (Parigi et al., 2015). This awareness led us to a cautious attitude. We did not want to burden the trainees with the impact of ICT; instead, we relied on the mediation skills of tutors to stimulate discussion based on the inputs offered in the LPs. The monitoring of the courses ${ }^{3}$ has confirmed our expectations, giving a positive picture, and moreover, has helped to define the sociocultural profile of our trainees:

- $90.8 \%$ of trainees are women;

- $42 \%$ of these have less than 15 years of teaching experience;

- $\quad$ the median age is 49 years (range: $30-69$ years);

- with respect to other courses of NOP, our trainees (teachers of FL) declare difficulty in finding a balance between course attendance and daily activities. This could be because, often, the teachers of FL have a daily agenda fragmented among many classes and even schools;

- the LPs are greatly appreciated for their operational dimension and the quality of the contents;

\footnotetext{
${ }^{3}$ For more information, go to:http://formazionedocentipon.indire.it/?p=1020
} 


\section{Innovations in the continuing professional development of foreign language teachers: from blended learning to visual-based learning, choices of emotional and instructional designs Toci}

- in the context of the use of the online platform, the tendency to use traditional tools of computer-mediated communication (email, forums) is seen, but the logic of the Web 2.0 finds little space and, for instance, blogs and wikis are not used.

\section{The evolution of form and content between VBL and emotional designs}

When the Ministry of Education asked INDIRE to integrate the project, we based our work on previous experience. Nonetheless, changes were required. The range of technologies available for use in language learning and teaching has become broad; the advent of Web 2.0 with its tools (blog, wiki, video-sharing, etc) enables learners to consume and produce contents. At the international level, the potentialities of these tools were already known, from mobile devices (Thorne \& Pyne, 2005; De Wever et al., 2007; Kukulska-Hulme \& Shield, 2008), to social networks, communities and blogs that enable more interactions with native speakers, to wikis for shared contents that allow collaborative linguistic activities (Wang \& Vàsquez, 2012). We also need to consider that many teachers wrongly assume that students are capable of dealing with social media. This is why, even in Italy, scholars stress the necessity to teach students how to deal with new media (Galliani \& Maragliano, 2002; Rivoltella, 2001)

For these reasons, we had to guide the teachers to the discovery of the potential of Web 2.0 and MALL; we had to develop aspects of instructional design of the online training contents, providing more support to trainees. Finally, because it was impossible to activate courses, the LPs would be used in situations of non-formal learning and so should be more clear and 'talking'. Considering our aim, some of the changes that were becoming common in the fields of continuing education and didactics of linguistic disciplines offered elements of reflection. In the new LP, we had to take into account the three levels of emotional design that Norman (2004) defines and through which we 'read' experiences.

Table 1. Emotional design, adapted from Norman, D. A. (2004). Emotional design: Why we love (or hate) everyday things. Basic books.

\begin{tabular}{ll}
\hline $\begin{array}{l}\text { Visceral } \\
\text { designs }\end{array}$ & $\begin{array}{l}\text { It depends on the emotional impact and appearance. The choices should mainly be designed to capture attention positively. The } \\
\text { attractiveness and relevance of solutions in terms of communication and visual design become fundamental. }\end{array}$ \\
\hline $\begin{array}{l}\text { Behavioural } \\
\text { designs }\end{array}$ & $\begin{array}{l}\text { It depends on the experience of use, functionality and usability. In the case of existing products, the first step in a good behavioural } \\
\text { design is to understand precisely the way people will use the product. } \\
\text { But with a new product, all consequences are possible. Pleasantness must capture the user, but its architecture, its organization and } \\
\text { logic interface affect the function and usability of the product. The balance designed between interface and visual elements become } \\
\text { directly responsible not only in the comprehension but also in the way of use and its interpretation by the user. }\end{array}$ \\
\hline $\begin{array}{l}\text { Reflective } \\
\text { designs }\end{array}$ & $\begin{array}{l}\text { This is the deepest level. It depends on the culture and is based on the content, the message and the meaning that is being constructed } \\
\text { beyond the initial experience of use. }\end{array}$ \\
\hline
\end{tabular}

For the designers of INDIRE, the development of these levels meant working on the crucial element, the content, along with complementary work on the other aspects related to visceral and behavioural designs, forms and usability. In particular, the following were the features:

- In relation to the contents, the basis of the reflective designs, the new LP should help the teacher in daily work, enhance his/her capacity to project and reflect on the activities. Furthermore, the LP should be characterized by the operational dimension, with the exemplification of uses of ICT and new media, in a pedagogical perspective, helping the teacher in his/her choice.

- In relation to the behavioural design, the promotion of the use of ICT among teachers has always been an institutional goal for INDIRE. Now, the opportunity to deliver training with the flexibility of the mobile and the tools of Web 2.0 opened new perspectives for the achievement of this target. We then strategically decided to take advantage of video language to ensure a first 'visceral' impression, useful to engage the user, and to attain the training objectives. In this sense, the video had to assume the same dignity and explanatory value entrusted exclusively to textual language until now.

- In relation to the visceral design, in the past years, the potential of Web 2.0 for creating and sharing video has boosted the use of this medium within the field of education: Massive Open Online Courses (MOOCs), Khan Academy and discipline-wise blogs are examples wherein videos are used to engage and guide the learning dimension of self-directed study. Currently, the VBL '...is now recognized by technology-enhance learning researchers as a powerful learning resource for online teaching activities' (Yousef, Chatti \& Schroeder, 2014).

The help provided by images, audio and video in the learning process is the subject of the theories developed by researchers on the psychology of learning media. According to Dale (1969), we remember 10\% of what we read, 30\% of what we see and $50 \%$ of what we see and hear at the same time. However, this does not imply that the audio -video resource represents a sure added value to learning: the theories of cognitive load (Chandler \& Sweller, 1991) and multimedia learning (Mayer \& Moreno, 2003) have highlighted potentialities and risks.

The first reflection on the use of audio -video in our contents brought us to the implementation of a taxonomy based on the training and communication goals (Toci et al., 2015).

In the context of continuous professional development, communication style and format of transmission have to correspond to both the context and the training needs described herein. With the video, we can compensate for the lack of the communicative immediacy of the tutor through the following: 


\section{Innovations in the continuing professional development of foreign language teachers: from blended learning to visual-based learning, choices of emotional and instructional designs Toci}

- the iconic language - can be clarified and drawn to the attention of the learner, as the tutor would do with gestures;

- the motivational aspects - the emphasis given to key questions by the tutor can find a new form in the video.

Moreover, we needed to implement a high-quality voice-over and audio in the various languages, because the LP had to be focused on the use of language as a concrete vehicle for communication.

\section{Innovations of the model: architecture and purpose of the video}

Starting from the taxonomy described earlier, the types of videos identified as more suitable for our purposes were as follows:

- video to turn attention;

- $\quad$ video to explain and show.

Recent meta-analyses (Winslet, 2014; Yousef et al., 2014) have shown that video is frequently used in VBL for 'engaging' purposes. It was useful in our case, oriented toward the publication of the training contents in an open environment, to work on the dimensions of the emotional and visual designs (Norman, 2004) and to capture the attention of the learner presenting the LP in a more attractive way. The introductory video had to meet various needs:

- offering to the learner an 'advance organizer' (Ausubel, 2004), providing a conceptual anchor through the anticipation of the main information and educational goals;

- enhancing 'experiential and situated learning', based on the principles of adult learning (Cercone, 2008). We started from a concrete problem of the teacher, in order to explicate utility and contiguity with respect to professional life, e.g. How can I design a syllabus? How can I evaluate the language skills?

On this basis, we identified the following contents for the introductory video:

- a general description and aim;

- $\quad$ an educational goal for teachers and their students;

- a description of the ICT and the strategy proposed and their added value with respect to the target problem.

Recent studies on the behaviour of users when viewing videos, based on big data collected on the MOOCs, have shown how the anticipation and subsequent focus on new content helps to retain the attention of the viewer (Guo et al., 2014). To facilitate understanding, the LPs have been organized sequentially, giving space to the two conceptual units: problems and strategies. In the first step of the LP, we have dedicated a video, titled WHY, to the problem and the definition of the educational issue. Key questions have been used to trigger the reflective process on the content's core.

In the second video, titled HOW \& WHAT, the questions asked before find an operational answer, through the explanation of possible instructional practices, strategies and tools. The contents are then summarized in the last video, SYNTHESIS. In conclusion, the first step represents the core of the LP, while the last two assume a more instrumental function.

In summary, in the new model, the teaching approach remained constant, whereas more innovative elements have been developed in terms of design and architecture. 
Innovations in the continuing professional development of foreign language teachers: from blended learning to visual-based learning, choices of emotional and instructional designs Toci

\begin{tabular}{|c|c|c|c|c|}
\hline Recipients & \multicolumn{4}{|c|}{ Upper secondary school teachers of FL } \\
\hline Context of use & \multicolumn{4}{|c|}{ Self determinedleaming } \\
\hline $\begin{array}{l}\text { Methodological } \\
\text { and training } \\
\text { approach }\end{array}$ & \multicolumn{4}{|c|}{$\begin{array}{l}\text { In additions to the above: } \\
\text { - greater cognitive scaffolding in conveying the content; } \\
\text { - centering on theoretical and practical nature of the glottodidactic }\end{array}$} \\
\hline Content & \multicolumn{4}{|c|}{$\begin{array}{l}\text { In additions to the above: } \\
\text { proposals for use of ICT and web } 2.0 \text { for teachers and with students }\end{array}$} \\
\hline Design & \multicolumn{4}{|c|}{$\begin{array}{l}\text { - In additions to the above: more attention to aspects of emotional design; } \\
\text { - equal dignity of language video and written text; } \\
\text { - hypertext structure with video sequences and static pages with dornloadable materials. }\end{array}$} \\
\hline Architecture & $\begin{array}{l}\text { Description } \\
\text { Video-Introduction: } \\
\text { General aim; } \\
\text { Definition of the } \\
\text { problem and } \\
\text { educational issue } \\
\text { Teachers' and Students' } \\
\text { learningobjectives. }\end{array}$ & 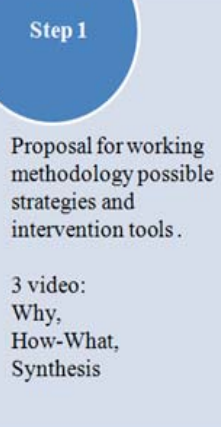 & $\begin{array}{l}\text { Resources and } \\
\text { documentation necessary } \\
\text { for the activity in } \\
\text { classroom }\end{array}$ & $\begin{array}{l}\text { Assessment tools for } \\
\text { teachers' and students' } \\
\text { learning outcome. } \\
\text { Short summary in } \\
\text { Italian. }\end{array}$ \\
\hline
\end{tabular}

Fig. 2 The new model of the learning paths

\section{The choices of visual design, feasibility and sustainability: video animations versus video interviews}

The videos should treat complex arguments in a short time and in a simple way. For this reason, in the design and writing phase, we have given indications to guide the authors and to ensure a truly customized design of the product. The main points are summarized in the following table (Fig. 3):

\begin{tabular}{|c|c|c|}
\hline Style & Suggestions & Characters/Viewing time \\
\hline $\begin{array}{l}\text { short interview, } \\
\text { neutral language style, } \\
\text { linear articulation with } \\
\text { questions and answers } \\
\text { designed to center the main } \\
\text { theme }\end{array}$ & $\begin{array}{l}\text { - Highlight the salient } \\
\text { concepts by proposing: } \\
\text { - keywords, } \\
\text { - diagrams, } \\
\text { - animations, images } \\
\text { contextual with the voice } \\
\text { of the interview } \\
\text { - other }\end{array}$ & $\begin{array}{l}\text { - } 4 \text { videos, total } 16 \text { min., } \\
\text { viewing time from } 8 \text { to } 1 \\
\text { min.) } \\
\text { - Introduction: } \max 4000 \\
\text { characters (about } 4 \text { min.) } \\
\text { - Why: } \max 2500 \\
\text { characters (about } 3 \text { min.) } \\
\text { - How and what: } \max 8000 \\
\text { characters (about } 8 \text { min.) } \\
\text { - Summary: } \max 1000 \\
\text { characters (about } 1 \text { min.) }\end{array}$ \\
\hline
\end{tabular}

Fig. 3 Main points of the video guidelines

In total, 32 LPs were needed to cover the curriculum in the four target FLs. To ensure flexibility in their use, the videos should have good graphics and sound, in addition to being embedded in a responsive template that automatically adjusts to fit the size of a browser window of any device. 


\section{Innovations in the continuing professional development of foreign language teachers: from blended learning to visual-based learning, choices of emotional and instructional designs Toci}

Regarding the choice of style and mode of implementation, we had two possibilities:

- video interviews with the authors, accompanied by animated graphics, pictures representing complex information;

- video clips in the form of video animation.

Since the mid-2000s, studies have shown greater appreciation and, in some cases, greater effectiveness in learning using videos characterized by dynamism, provided by the complementary use of animations and changes of sequences (Zhang, 2005; Chen, 2012).

We then made a number of prototypes according to these two models, to investigate the possible problems in terms of sustainability and technical feasibility.

In the first case, the interview was carried out in a movie studio with an author, a teacher of Spanish and a native speaker. First of all, with the teacher and the team, we shared the screenplay for the video recording in chroma key mode; then during post-production, in collaboration with the author, the designer and the developer, we included the graphics elements and the animations useful to convey content. Due to the communication skills of the teacher and the quality of the audio - video, graphics solutions proposals were 'limited' and were used to support the understanding of the content.

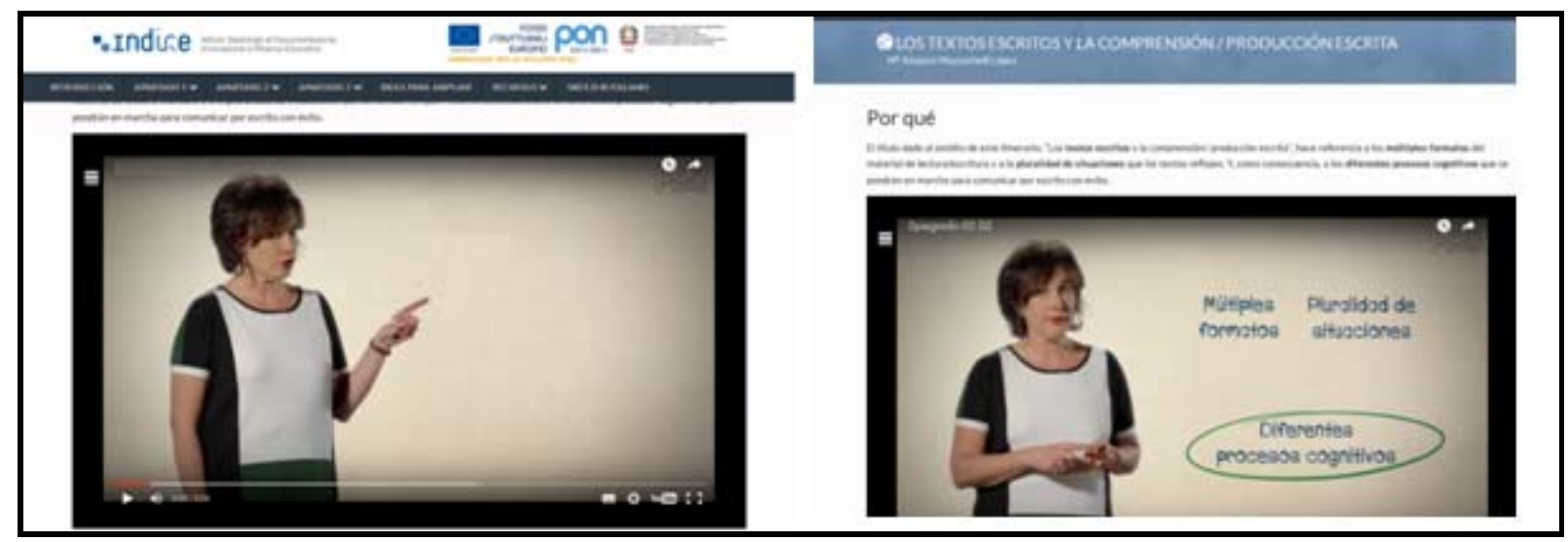

Fig. 4: Shooting video on the left, to the right the video with the integration of animations and video-scribing in post production Learning paths, INDIRE, online: http://forum.indire.it/repository/working/export/6515/index.html

Even though the technical quality was guaranteed by the team and the equipment, the variable provided by the teacher affected the final result greatly. The costs were directly dependent on the communication skills of the protagonist, often facing a movie set for the first time. Furthermore, this added the requirement for good pronunciation by native speakers.

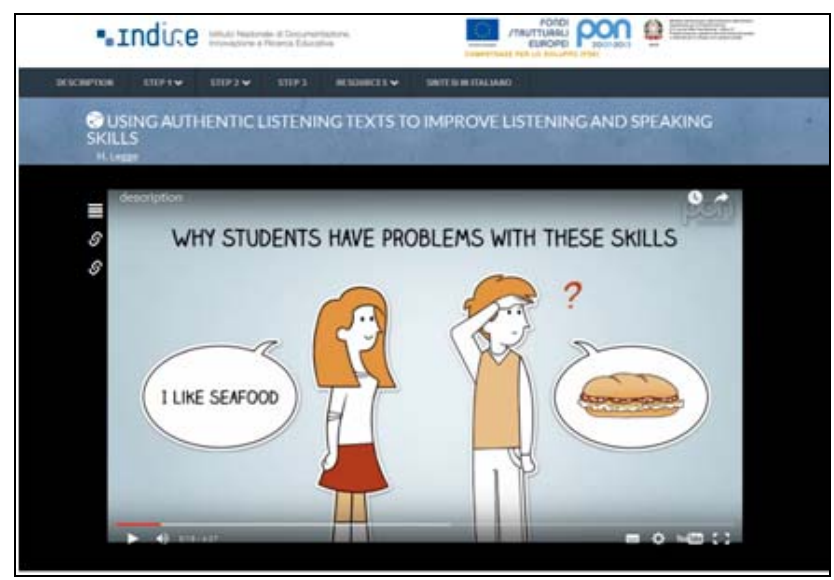

Fig. 5 Video animations -INDIRE, online: http://forum.indire.it/repository/working/export/6516/index.html

In the field of the linguistic disciplines, the use of video and video animation is normal and responds to multiple purposes and targets (Musa et al., 2013). As shown in various studies mentioned in Yousef et al. (2014), the impact on teaching and learning outcomes is positive.

Considering the usability and accessibility of a video, important for the reflexive and behavioural designs, we have used animation to assist the cognitive process (Kuomi, 2006) using graphic elements to capture the visual attention (Mayer \& Anderson, 1991; Mayer \& Moreno, 2003; Chen, 2012). In the explanations, the gestures of the interviewed 


\section{Innovations in the continuing professional development of foreign language teachers: from blended learning to visual-based learning, choices of emotional and instructional designs Toci}

author have been replaced by video animations, which required a complex work of design and implementation, but with positive and sustainable results.

Suggestions from the authors about the script were interesting from the disciplinary point of view, but obviously not necessarily corresponding to the point of view of the multimedia design. Similarly, the graphic designer and developer could misunderstand the content due to misinterpretation of the LP and the lack of disciplinary knowledge. The role of the team of researchers of INDIRE, designers of training and disciplinary experts, was then to 'harmonize' the asymmetry between these dimensions. With the video, we could compensate the lack of communicative immediacy of the tutor by establishing the balance between emotional and instructional design aspects, granting acceptability to the identified training model on which we based the implementation of the entire curriculum of the training.

For the sustainability of the process, we opted for the solution of video animation.

Regarding the visual design, we were inspired by the essentiality of LeFever (2012), creator of the instructional video format, able to explain complex issues in a short time, with a minimalist drawing style. We also added the technique of video scribing and whiteboard animation (a new form of visual storytelling with hand-drawn line arts, texts or cartoons to illustrate the topic). The simplicity of the lines and the common characterization of the characters in all the videos have a double benefit: communicative for easy recognition by the user, and technical with the creation of a graphic repository shared with all the developers, which allowed significant savings in terms of time and cost. The implementation of other aspects of video scribing and whiteboard animation, as well as use of keywords, infographics, etc, allowed the highlighting of concepts, scanning of conceptual sequences and creation of a dynamic visual flow.

In the case of inappropriate design choices, we were always able to intervene during the development phase, whereas modifying the video interview would have been more expensive. Conversely, it became impossible to use the audio recordings of native speaker authors directly due to their poor quality, which were thus replaced with professional voice-over recordings. Indeed, the audio is a key element that, if neglected, affects the usability (Guo et al., 2014).

The features of the production of the past two years are depicted below.

Table 2. Summary of actions, needs and professionals involved for each type of product

\begin{tabular}{llll}
\hline Needs & Hypertext & Video interview & Video animation \\
\hline Movie studio & $X$ & $X$ & $X$ \\
Professional voice-over & $X$ & & \\
HTML Web developer & & Low & Low \\
Graphic & Low & High & Very high \\
Web graphic designer for animation & Low & High & Very high \\
Storyboarding & Medium & High & Very high \\
Project coordination & Medium & High & High \\
Video dynamism and interactivity & Low & $X>$ & Medium \\
Video modifiability & X> & Only link to external video & Almost impossible, requiring the physical presence of the author \\
& & & \\
\hline
\end{tabular}

Besides the specific visual design issues (cartoons, 3D graphics, etc) the low cost and ease of implementation of video animations (Adamo-Villani et al., 2014; Lin,. 2011; Ainsworth \& Van Labeke, 2004) are widening the perspectives for the use of this format for the following purposes:

- $\quad$ to deliver content online for a flipped-classroom approach (Popescu, et al., 2014; Vieira et al., 2014);

- to develop typical scenarios of teachers' profession, aimed at the improvement of skills of observation and management of relational dynamics in the classroom (Herbst et al., 2011; Smith et al., 2012);

- $\quad$ to propose role play for the development of communication skills (Croft et al., 2014).

\section{Results}

As we have seen, the link between media and education has deep roots: according to Thomas, 'Over the last 20 to 30 years, language learning has become one of the most popular and dynamic areas of education for the application of learning technologies' (Thomas et al., 2013). Today, more than ever before, the interest of the scientific and educating community is particularly intense due to the advent of Web 2.0. As is well known, technology in itself does not teach nor does it make a teacher better or worse, but it can play a role, opening interesting perspectives in the language classroom. For these reasons, we have developed a curriculum to help teachers to discover how to teach with digital media, as well as promoting collaboration, production and communication in FL in their classrooms, and to help them how to choose, with critical consciousness, media and tools for their students and appropriate objectives, keeping an eye on the media literacy.

All LPs, before the multimedialization, have been subjected to a validation process (entrusted to selected teachers) focused on quality of the content, functionality and usability at school. In particular, these three dimensions have been structured in 17 indicators. To facilitate the survey, each indicator has been in turn articulated as four descriptors on four levels (one being the poorer, four the better). The quantitative analysis of the frequencies shows a positive picture, with clear predominance of the descriptor levels three and four. 


\section{Innovations in the continuing professional development of foreign language teachers: from blended learning to visual-based learning, choices of emotional and instructional designs Toci}

From the point of view of the visual design, recent studies seem to support our choices: indeed, recent research based on the analysis of big data collected on the MOOC video courses shows that proper duration, fragmentation of content, variety of the script and the proposed interactions are key elements in drawing and maintaining the user attention (Hibbert. 2014, Guo et al., 2014). On the other hand, research on the effectiveness of the training video animation, compared to video recordings with actors, does not provide evidence for substantial differences between the two solutions. The cornerstone is instead increasingly identified in the fulfilment of the most basic principles of the hereinmentioned theories about the learning process and the instructional designs (Chandler \& Sweller, 1991; Mayer \& Moreno 2003; Frey, 2010) and in the accuracy of the design.

Recent studies (Um et al., 2012; Thurairaj \& Roy, 2012) have opened interesting perspectives demonstrating that increased care with the emotional design can positively affect the learning and motivation of the learner.

The next step that we want to accomplish with the widespread use of our LP and videos is to monitor and evaluate the effectiveness of the videos in communication and in the learning process. Compared to the principles followed in the design and approach to our goals, we will investigate about communication effectiveness, motivation and training. For example, compared to the three dimensions of Norman's emotional design, our new LP will be evaluated against the following criteria.

Table 3. Emotional design and evaluation criteria

\begin{tabular}{ll}
\hline Visceral designs & $\begin{array}{l}\text { LP and video meet with consumer tastes } \\
\text { The videos are pleasant for our teachers } \\
\text { Trigger motivation and satisfaction in learning } \\
\text { Behavioural designs } \\
\text { Are easy to use } \\
\text { Anticipate the needs of the teachers } \\
\text { Encourage the use of the mobile and devices with Web 2.0 }\end{array}$ \\
& $\begin{array}{l}\text { Stimulate positive emotions that encourage motivation and learning } \\
\text { Facilitate and improve the understanding of the content } \\
\text { Constitute real added value compared to those with only hypertext and images }\end{array}$ \\
\hline
\end{tabular}

\section{References}

Adamo-Villani, N., Cui, J., \& Popescu, V. (2014). Scripted Animation Towards Scalable Content Creation for eLearning-A Quality Analysis. In E-Learning, E-Education, and Online Training (pp. 1-9). Springer International Publishing.

Ainsworth, S., \&Van Labeke, N. (2004). Multiple forms of dynamic representation. Learning and instruction, 14(3), 241-255. http://dx.doi.org/10.1016/j.learninstruc.2004.06.002

Ausubel, D. P. (2004). Educazione e processi cognitivi. Guida psicologica per gli insegnanti (Vol. 25). FrancoAngeli.

Cercone, K. (2008). Characteristics of adult learners with implications for online learning design. AACE journal, 16(2), 137-159.

Chandler, P., \& Sweller, J. (1991). Cognitive load theory and the format of instruction. Cognition and instruction, 8(4), 293-332.

Chen, Y. T. (2012). The effect of thematic video-based instruction on learning and motivation in e-learning. International Journal of Physical Sciences, 7(6), 957-965.

Coscia, L. (2016). Linguaggi per la formazione: dall'ipertesto al video. In PON Lingua, letteratura e cultura in una dimensione europea - Area Lingue straniere. Attuazione, risultati e prospettive, (pp. 85-91). Firenze: INDIRE. Retrieved from: http://mediarepository.indire.it/iko/uploads/allegati/O2NADO7D.pdf

Croft, H., Rasiah, R., Cooper, J., \& Nesbitt, K. (2014). Comparing Animation with Video For Teaching Communication Skills. In Proceedings of the 2014 Conference on Interactive Entertainment (pp. 1-10). ACM

Dale, E., Audiovisual Methods in Teaching, 1969, NY: Dryden Press.

Frey, B. A., \& Sutton, J. M. (2010). A model for developing multimedia learning projects. Merlot journal of online learning and teaching, 6(2).Retrieved from http://jolt.merlot.org/vol6no2/frey_0610.pdf

Guo, P. J., Kim, J., \& Rubin, R. (2014). How video production affects student engagement: An empirical study of mooc videos. In Proceedings of the first ACM conference on Learning@ scale conference (pp. 41-50). ACM.

Herbst, P., Chazan, D., Chen, C. L., Chieu, V. M., \& Weiss, M. (2011). Using comics-based representations of teaching, and technology, to bring practice to teacher education courses. ZDM, Mathematics Education, 43(1), 91103. http://dx.doi.org/10.1007/s11858-010-0290-5

Hibbert, M. C. (2014). What Makes an Online Instructional Video Compelling?.Educause Review Online.

Retrieved from http://www.educause.edu/ero/article/what-makes-online-instructional-video-compelling

Kukulska-Hulme, A., \& Shield, L. (2008). An overview of mobile assisted language learning: From content delivery to supported collaboration and interaction. ReCALL, 20(03), 271-289.

Kuomi, J. (2006). Designing Video and Multimedia for Open and Flexible Learning. Oxford: Routledge. 


\section{Innovations in the continuing professional development of foreign language teachers: from blended learning to visual-based learning, choices of emotional and instructional designs Toci}

LeFever, L. (2012). The Art of Explanation, Enhanced Edition: Making your Ideas, Products, and Services Easier to Understand. John Wiley \& Sons.

Lin, H. (2011). Facilitating learning from animated instruction: Effectiveness of questions and feedback as attentiondirecting strategies. Journal of Educational Technology \& Society, 14(2), 31-42.

Mayer, R. E., \& Anderson, R. B. (1991). Animations need narrations: An experimental test of a dual-coding hypothesis. Journal of educational psychology, 83(4), 484.

Mayer, R. E., \& Moreno, R. (2003). Nine ways to reduce cognitive load in multimedia learning. Educational psychologist, 38(1), 43-52.

Galliani, L., Maragliano, R. (eds.)(2002). Educazione ai media, "Studium Educationis", 3, 73-76.

Musa, S., Ziatdinov, R., \& Griffiths, C. (2013). Introduction to computer animation and its possible educational applications. arXiv preprint arXiv:1312.1824.

Norman, D. A. (2004). Emotional design: Why we love (or hate) everyday things. New York: Basic Books

Popescu, V., Adamo-Villani, N., Wu, M. L., Rajasekaran, S. D., Alibali, M. W., Nathan, M., \& Cook, S. W. (2014). Animation Killed the Video Star. In Proceedings of CHI 2104 Workshop on Gesture-based Interaction Design: Communication and Cognition Toronto, Canada, April 2014. ACM Digital Library, 55-59.

Parigi L., Rossi F. (2010) Italy: Ict and In Service Teacher Training - Blended E Learning Provided by Punto Edu. In Balanskat, A., \& Gertsch, C. A. (2010). Digital Skills Working Group. In Review of national curricula and assessing digital competence for students and teachers: Findings from 7 countries. European Schoolnet Brüssels.

Parigi L, Di Stasio M., Mangione M.G., Pettenati M.C., Formiconi A., Guasti L, Russo C, Federici G., Faggioli M (2015). Bridging formal and informal learning in teachers professional development: experiences and innovative environments. In Falcinelli, F., Minerva, T., \& Rivoltella, P. C. (Eds.), Apertura e flessibilità nell'istruzione superiore: oltre l'E-Learning? Proceedings of the X Convegno della Società Italiana di e-learning, Perugia, 1314-15 Novembre (pp. 210-229). Reggio Emilia: SIe-L editore.

Rivoltella, P.C. (2001). Media Education. Roma: Carocci.

Smith, D., McLaughlin, T., \& Brown, I. (2012). 3-D Computer Animation vs. Live-Action Video: Differences in Viewers' Response to Instructional Vignettes. Contemporary Issues in Technology and Teacher Education, 12(1), 41-54.

Thomas, M., Reinders, H. and Warschauer, M. (Eds) (2013),Contemporary Computer-Assisted Language Learning, Bloomsbury, London

Thorne, S. L., \& Payne, J. S. (2013). Evolutionary trajectories, Internet-mediated expression, and language education. CALICO journal, 22(3), 371-397.

Yousef, A. M. F., Chatti, M. A., \& Schroeder, U. (2014). Video-Based Learning: A Critical Analysis of The Research Published in 2003-2013 and Future Visions. In eLmL 2014, The Sixth International Conference on Mobile, Hybrid, and On - line Learning, 112 - 119

Toci, V., Camizzi, L., Goracci, S., Borgi, R., De Santis, F., Coscia, L.,Perrone F., Cigognini E., Pettenati, M. C. (2015). Designing, producing and exemplifying videos to support reflection and metacognition for in-service teachers training. Journal of e-Learning and Knowledge Society, 11(2).

Thurairaj, S., \& Roy, S. S. (2012). Teachers' emotions in ELT material design. International Journal of Social Science and Humanity, 2(3), 232-236. Retrieved from: http://www.ijssh.org/papers/101-CH228.pdf

Um, E., Plass, J. L., Hayward, E. O., \& Homer, B. D. (2012). Emotional design in multimedia learning. Journal of Educational Psychology, 104(2), 485-498.

Vieira, I., Lopes, A. P., \&Soares, F. (2014). The potential benefits of using videos in higher education. IATED Publications,. 750-756.

Wang, S., Vásquez, C.(2012) Web 2.0 and second language learning: What does the research tell us. CALICO journal, 29(3), 412-430.

Wever, B. D., Mechant, P., Veevaete, P., \& Hauttekeete, L. (2007, December). E-Learning 2.0: social software for educational use. In Multimedia Workshops, 2007. ISMW'07. Ninth IEEE International Symposium on, 511-516.

Winslett, G. (2014). What counts as educational video?: Working toward best practice alignment between video production approaches and outcomes. Australasian Journal of Educational Technology, 30(5). Retrieved from: http://ajet.org.au/index.php/AJET/article/view/458/1075

Zhang, D. (2005). Interactive multimedia-based e-learning: A study of effectiveness. The American Journal of Distance Education, 19(3), 149-162. 